\title{
Determinants of integrated soil fertility management technologies adoption by smallholder farmers in the Chinyanja Triangle of Southern Africa
}

Powell Mponela $^{\mathrm{a} *}$, Lulseged Tamene ${ }^{\mathrm{a}}$, Gift Ndengu ${ }^{\mathrm{a}}$, Nelson Mango ${ }^{\mathrm{a}}$

${ }^{a}$ International Center for tropical Agriculture (CIAT)

\begin{abstract}
Integrated Soil Fertility Management (ISFM) technologies have proven to be viable options for improving land productivity and increasing yield. However, adoption of the set of complementary technologies that are required in ISFM is quite variable and studies of adoption focus on single technologies. This study of 10 technologies shows that farmers in Chinyanja Triangle use up to eight and cluster analysis revealed 3 groups. The clustering of nutrient dense technologies of inorganic fertiliser, compost and animal manure indicates that they are used by farmers facing similar constraints. Analysis of the determinants of adopting more than one ISFM technology using a pooled and random effects ordered probit model shows that farmers' adopting a set of technologies have fragmented pieces of land, more literate household members, more farming experience, headed by males. Non-adoption has been associated with ownership of large parcels of land and large family sizes. These results are instrumental in identifying factors that influence adoption of a set of ISFM technologies in the Chinyanja triangle and could be of use in research and development initiatives.
\end{abstract}

Keywords: ISFM choice set, technological combinations, adoption, ordered probit model, Chinyanja Triangle 


\section{Acknowledgements}

This work was undertaken by the International Center for Tropical Agriculture (CIAT), which forms part of, and funded by, the CGIAR Research Program on Dryland Systems. This paper has not gone through CIATs standard peer review procedure. The views expressed in this document cannot be taken to reflect the official opinions of CGIAR. 


\section{Introduction}

Soil health is of great importance to the African economies as farming is the main livelihood strategy for the majority of the population. So far, increases in food production to feed the growing population in sub-Saharan Africa (SSA) have been attained through agricultural extensification with little improvement to existing farmland (FAO 2014). In Cinyanja Triangle, land holdings are sub-diveded among siblings, presently owning 0.5 to 2.0 ha, which is small and it is becoming difficult to meet household food requirements with the existing low-input, lowoutput production practices (Amede et al. 2014). There is inequity in acquisition of land with wealthier farmers and estates owning larger parcels of prime arable soils (Sekeris 2010). The vulnerable farmers who constitute the majority of the agrarian community in the region cultivate margins of arable land and as demand grows, cultivation is extended into fragile and conserved areas (Lambin and Geist 2008). Some fields are cultivated without nutrient amendments leading to declining soil fertility and wider yield gaps (Chilimba et al. 2005). Due to these and other challenges such as climate change, farming families in SSA continue to face challenges of food insecurity and malnutrition with $23 \%$ of the population classed as hungry and $40 \%$ of children under age of five stunted (The Montpellier Panel 2013, UNICEF 2013). In SSA alone, malnutrition is estimated to affect about 38.6 million under-fives and is likely to grow to 41.6 million by 2015 if it remains unchecked (UNICEF 2013).

Research efforts to increase production per unit area through intensification are hampered by heterogeneity in local socio-economic and biophysical conditions across landscapes (The Montpellier Panel 2013). Some global research outputs that worked elsewhere, such as use of high yielding varieties and fertilisers, are failing to replicate their reported successes on poor farmers' plots (Mueller et al. 2012). The Integrated Soil Fertility Management (ISFM) 
framework posed by Vanlauwe et al. (2011) suggests progressive adoption of combinations of technologies can maximising agronomic use efficiency of the applied nutrients and improving crop productivity, owing to complementary effects of technologies including improved crop varieties, use of inorganic and organic fertilisers coupled with good husbandry practices. However, adaption of the various ISFM components to technological, household, farm, environmental and societal conditions seems to be a challenge, and adoption has been low. It is generally considered that the cause of low adoption is that most farming households in SSA are resource constrained (Chilimba et al., 2005; Mugwe et al., 2009). Farmers' choice to use a particular set of technologies on a farm is not only dictated by biophysical attributes, but also by socioeconomic situations which vary greatly resulting in heterogeneous farming patterns across a landscape (Yengoh 2012). Further land fragmentation among offspring has also shown to have negative effects on adoption of some soil fertility improving technologies such as agroforestry (Chinangwa 2006).

Most studies treat adoption as a binary choice of individual technology or combination of technologies while the extent of adoption is analysed using truncated Tobit models or Cragg's two step model (Akinola and Alene 2010, Wiredu et al. 2014, Kassie et al. 2015). The dichotomous models show the probability of adopting at least one technology (Mugwe et al. 2009, Asfaw et al. 2011) but do not distinguish between the farmers who adopt one technology and those who adopt multiple technologies. Moreover, defining the cut-off point between adopters and non-adopters is the main challenge in examining the factors that influence the level of adoption of ISFM as a package. Using the equation by Golob and Regan (2002), the choice set for combinations of ISFM technologies tend to be large and difficult to interpret the effects of explanatory variables on each of the technologies and their combinations. However, farmers 
often exploit multiple ISFM technologies and adopt a set of best fits as a package that provide a higher potential advantage of complementarities and sustainability in dealing with a multitude of production constraints (Marenya and Barrett 2007, Wiredu et al. 2014).

ISFM technology adoption is therefore inherently multivariate and dealing with it using binary and truncated methods exclude useful information about interdependent and simultaneous adoption decisions (Dorfman 1996). Moreover, there could be a problem of independence of irrelevant alternatives (IIA) (Freese and Long 2000). Studies using dummy variables assumes that inclusion or removal of some technology $\mathrm{C}$ in a farming system would not affect the odds of choosing individual technology A over B. However, human behaviour rarely adheres to IIA(Ray 1973) and in smallholder farming systems with low levels of aspiration, farmers choice of technology is largely influenced by the societal preference than own satisfaction (Le et al. 2012). We therefore use the number of ISFM technologies adopted to analyze multiple adoption decisions using a pooled and random effects ordered probit model (OPM). An understanding of socio-ecological determinants of a number of technologies is deemed crucial in designing optimal sets of technologies and out-scaling best fits for addressing multiple constraints in soil fertility and productivity.

The study was aimed at identifying factors that enhances adoption of ISFM technologies in Maize mixed cropping system of Chinyanja Triangle. To realise this overarching goal the study aims to address the following questions: (i) what are the common combinations of ISFM technologies employed by smallholder farmers in the study areas; (ii) which are the key farm and household attributes that drive farmers' decision to adopt a set of ISFM technologies. 


\section{Methodology}

\subsection{Study area}

The study was conducted in the Dedza and Ntcheu districts of Central Malawi, Macanga district of Mozambique and Mambwe district of Eastern Zambia (Figure 1). The Chinyanja Triangle is dominated by Nyanja people who share language dialects, similar beliefs, and history, suggesting similarities in approaches to resource utilisation and more importantly on land management (Amede et al. 2014). While land tenure regulations differ in the three study countries, usufruct rights at local scale are similar. Locally, chiefs are the custodians of land within the jurisdiction of their chiefdoms and it is shared/transferred mainly through a matrilineal lineage system (CGIAR, 2014).

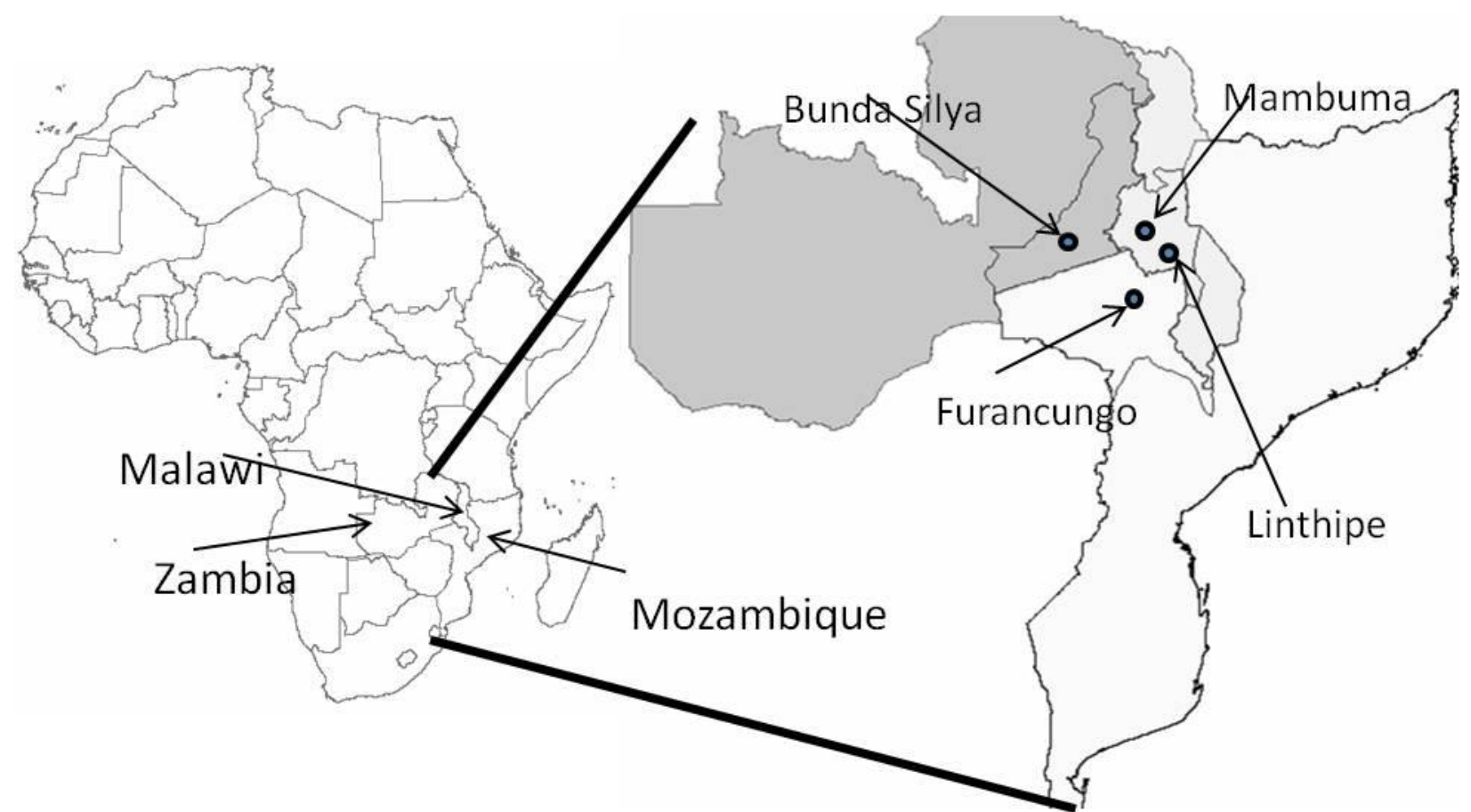

Figure 1. Map of the study site showing showing survey locations (dots) within the Chinyanja Triangle covering Eastern Province of Zambia, Central and Southern Regions of Malawi and Tete Province of Mozambique.

The Chinyanja Triangle has three distinct ecozones with plateaus on the northern end, subhumid escarpments around the centre and semi-arid Shire, Luangwa and Zambezi river valleys 
towards the south. The study was conducted in the sub-humid escarpments that face higher demand for cropland (Denning et al., 2009). The site falls within the maize mixed farming system (Dixon et al., 2001) extending across plateau and highland areas at altitudes of 800 to 1 500 metres, from Kenya and Tanzania to Zambia, Malawi, Zimbabwe, South Africa, Swaziland and Lesotho.

Maize is the main staple food while cash sources are migrant remittances, cattle, small ruminants, tobacco, and cotton, plus sale of maize and pulses (Myburgh and Brown 2006). Nsipe in Ntcheu District and Linthipe in Dedza district both in Malawi have been under cultivation for several generations. The Furancungo site in Macanga district of Mozambique and Budula-siliya in Mambwe district of Zambia have recently been re-settled and newly opened, respectively. Population densities (persons $\mathrm{km}^{-2}$ ) are lower 9 and 13 in Macanga and Mambwe but relatively higher 138 and 172 in Ntcheu and Dedza districts respectively (Republic of Zambia 2012, Republica de Mocambique 2005, Republic of Malawi 2008). Land holdings also vary from 0.5 ha in the south of Malawi to 2.0 ha in Zambia and Mozambique (Amede et al. 2014)

\subsection{Sampling strategy and data collection}

The study was conducted in areas sampled for the CGIAR Research Program on Dryland Systems and Africa RISING projects. Households were sampled from the sampling framework that was developed for land degradation surveillance framework (LDSF), which uses multistage spatially stratified random sampling of plots in a landscape (Vagen et al. 2013). The sentinel site covers an area of $10 \mathrm{~km} 2$ within which 16 clusters are stratified. Each cluster cover an area of 2 km2 with 10 randomly located sampling plots from where LDS was conducted. Five households were randomly drawn from the list of owners/users of the 10 plots thereby geo-referencing farmers to the sampled plots, clusters and sentinel sites. 
A household survey was conducted to collect primary household socio-economic data using a structured questionnaire. The data collected from 320 households included ISFM technology use, socio-demographic and economic characteristics of the households, land characteristics and resources endowments. Trained extension service personnel, agriculture research officers and enumerators collected data between December 2012 and June 2013. Before initiating the survey, the head of local Extension led the team for a daylong awareness campaign to seek support and collaboration from traditional leaders and their subjects. Local Extension Service personnel were instrumental in establishing a better working relationship on the ground.

\subsection{Analytical framework}

Complexity of ISFM technologies in the form of (a) multiple interacting inputs and outputs, (b) temporal variability, (c) multiple economic contributions, and (d) off-farm impacts pose analytical challenges. The schematic framework by Vanlauwe et al. (2011) proposes stepwise knowledge paradigm shifts from current practice, characterized by traditional varieties receiving too little and insufficiently managed nutrient inputs, to the full-fledged ISFM package. Vanlauwe et al. provide an operational definition of stepwise ISFM as: 'A set of soil fertility management practices that necessarily include the use of fertilizer, organic inputs, and improved germplasm combined with the knowledge on how to adapt these practices to local conditions, aiming at maximizing agronomic use efficiency of the applied nutrients and improving crop productivity. All inputs need to be managed following sound agronomic principles.' Some farmers are stagnating at the lower end of ISFM ladder (see Denning et al. 2009 and Vanlauwe et al. 2011) and most have moved to the second stage through use of improved germplasm plus inorganic fertilizers. The incorporation of locally available organic resources and adapting the globally/regionally proven technologies to local socioeconomic and biophysical conditions, at the third and fourth steps, has faced low adoption rates. 
A complete set of ISFM entails a combination of technologies rather than a single technology used in isolation. We employ hierarchical clustering using Wald's method to identify the most common combinations in the study sites (Cornish 2007). The procedure identifies homogeneous groups and form clusters based on maximising the variance between clusters of households using ISFM technologies (IBM 2012). Wald's clustering agglomerates the closest (i.e. least dissimilarity) pair of clusters. The dendrogram node heights (rescaled distance cluster combine) shows the numerical equivalences of agglomeration values. In addition to separating the clusters based on morphology, the cluster criterion values - the node heights - shows that the clusters are genuinely distantly related based on ultrametric distances (Murtagh and Legendre 2014). Height of each node in the plot is proportional to the value of the intergroup dissimilarity between its two daughters. Individuals or clusters with fewer similar observations are all plotted on the top nodes at lower height.

The cluster analysis reveals groups of technologies that farmers use probably due to complementarities. For complementary technologies, the probability of adopting the first is lower than that of the second, considering that the farmer after experiencing higher benefits from the first expects higher benefit also from the second (Lambrecht et al. 2014). In terms of technologies that require huge initial investment, the probability of adopting the second is higher than the first because as the number of technologies to adopt (and thus the resources to invest) increases, the risk also increases. Farmers who first are introduced to competing technologies also have lower probability of adopting more technologies. In this case, the dependent variable is ordinal. 


\subsection{Empirical model}

The ordered probit model is used to describe the latent variable for ISFM's frequency function $\left(\mathrm{T}^{*}\right)$. In this case we are able to cater for partial adopters since the dependent variable is ordered, the coefficients of the variables measure their direct effects along the distribution function. Thus the level of ISFM adoption $(T)$ by $i^{\text {th }}$ farm household $(i=1, \ldots, n)$ on plot $p(p=1, \ldots, p)$ is assumed to be determined by household and plot heterogeneity $\left(X_{\mathrm{ip}}\right)$ with unknown weight $(\alpha)$ and unobserved characteristic $\varepsilon_{\mathrm{ip}}$ as follows:

$$
\mathrm{T}_{\mathrm{ip}}=\mathrm{X}_{\mathrm{ip} \alpha}+\varepsilon_{\mathrm{ip}}
$$

The observed level of ISFM use is assumed to be related to the latent variable $\mathrm{T}^{*}$ ip as demonstrated by McKelvey and Zavoina (1975):

$$
\mathrm{T}_{\mathrm{ip}}=\mathrm{J} \text { if and only if } \mathrm{U}_{\mathrm{j}} \leq \mathrm{T}^{*}{ }_{\mathrm{ip}}<\mathrm{U}_{\mathrm{j}+1}, \text { for } \mathrm{j}=0, \ldots, \mathrm{j}
$$

Where $\mathrm{J}$ is the number of ISFM technologies adopted. $\mu_{\mathrm{j}}, \ldots \mu_{\mathrm{j}+1}$ are the estimated threshold levels. This equation states that if the number of ISFM technologies $\mathrm{T}^{*}{ }_{\text {ip }}$ lies between $\mu_{0}$ and $\mu_{\mathrm{j}+1}$, the response to the question on number of ISFM adopted is taken to be equal to $\mathrm{j}\left(\mathrm{T}_{\mathrm{ip}}=\mathrm{j}\right.$ ). Parameter vectors $\alpha$ and $\mu$ are estimated by maximum likelihood.

\subsection{Explanation of dependent variables used in empirical models}

Meta-analyses and literature reviews of agricultural, forestry and land management technologies have grouped factors influencing adoption of technologies using socio economic and ecological hypotheses into six categories namely: farmer preferences, resource endowments, market incentives and policies, biophysical and technological factors, and learning cost and risk aversion (Pattanayak et al. 2003). Preferences define the objectives and motivations of the economic agents choosing technologies while resource endowments enable their technology choices. Market incentives and bio-physical factors condition the extent, timing and nature of the 
technology choices while risk and uncertainty governs farmer's expectation in favor of investments that pay dividends only in the short run.

Farmer preferences are difficult to measure; hence socio-demographic proxies including age, education, and social status are used instead. Studies have found differing influences of these attributes hence it is not possible to, a priori, set the direction of effect (Pattanayak et al. 2003). Resource endowments measure the resources available to the technology adopter for implementing the new technology. In this study, variables that proxy's resource endowments include family labour, off-farm employment, land resources and asset based household wealth index. Generally, resource endowments are likely to be positively correlated with the probability of adoption (Marenya and Barret 2007, Mugwe et al 2009). However, the counter hypothesis states that increasing scarcity of fertile arable lands leads to higher shadow prices, causing farmers to prefer resource-conserving technology such as ISFM (Foltz 2003).

The household wealth index was constructed using asset-based models to reflect longer-run household wealth (Filmer and Pritchett 2001). Multi-dimensional data reduction method of Principal Component Analysis (PCA) was used to derive wealth index (Vyas and Kumaranayake 2006). Variables used included a set of dummy variables accounting for the nature of dwelling houses, count variables of durable goods, agricultural equipment and livestock owned. The different livestock species were converted into standard livestock units (LU) using nutritional and feed requirement factors for sub-Sahara Africa (Chilonda and Otte 2006).

Bio-physical factors relate to influences on the physical production process associated with farming. In general, poorer bio-physical production conditions such as declining soil fertility of small land holdings create a positive incentive to adopt technologies that will alleviate these situations (Ajayi et al. 2007). However, it is also possible that some farms are of a size that is 
below the threshold of useful investment and thus technology investment may not be worthwhile intervention (Guastella et al. 2013). Lower learning costs such as for farmers with access to information about the technology through better education, own experience from years of cultivation and participation in farmer groups enhances rapid spread of technologies (Marenya and Barret 2007). Farmers with little or no formal education face challenges in understanding the technical information about the technologies and are unwilling to take part in experimentation (Pattanayak et al. 2003). Given the long gestation period of ISFM technologies, best fits that offer lower risk and uncertainty in both short and long term are expected to be adopted easily (Odendo et al. 2010).

\section{Results and Discussion}

\subsection{Variability in usage of ISFM technologies within Chinyanja Triangle}

Usage of ISFM technologies varies greatly in the region but also among households (Figure 2). Inorganic fertilizer is widely used in the triangle by $68 \%$ of 312 households. This has been enhanced by fertiliser subsidies though application rates in the region are still low at 3.2, 8.4 and $30.8 \mathrm{~kg} \mathrm{ha}^{-1}$ for Mozambique, Zambia and Malawi, respectively (Morris et al. 2007). Higher proportion of households using inorganic fertilizers shows that most farmers are on the second stage of the ISFM technology adoption framework presented by Vanlauwe et al. (2011). Fertilizers are widely adopted because the immediate returns observed if applied to improved varieties are higher than when local varieties are used (Benson 1999; Holden 2013). Moreover, governments, NGOs and private sector promote combined use of fertilizer and improved varieties through input subsidies, credits and extension service (Fisher and Mazunda 2011). A 
recent survey by Kassie et al. (2015) found high and significant correlation between use of improved varieties and commercial fertilizers.

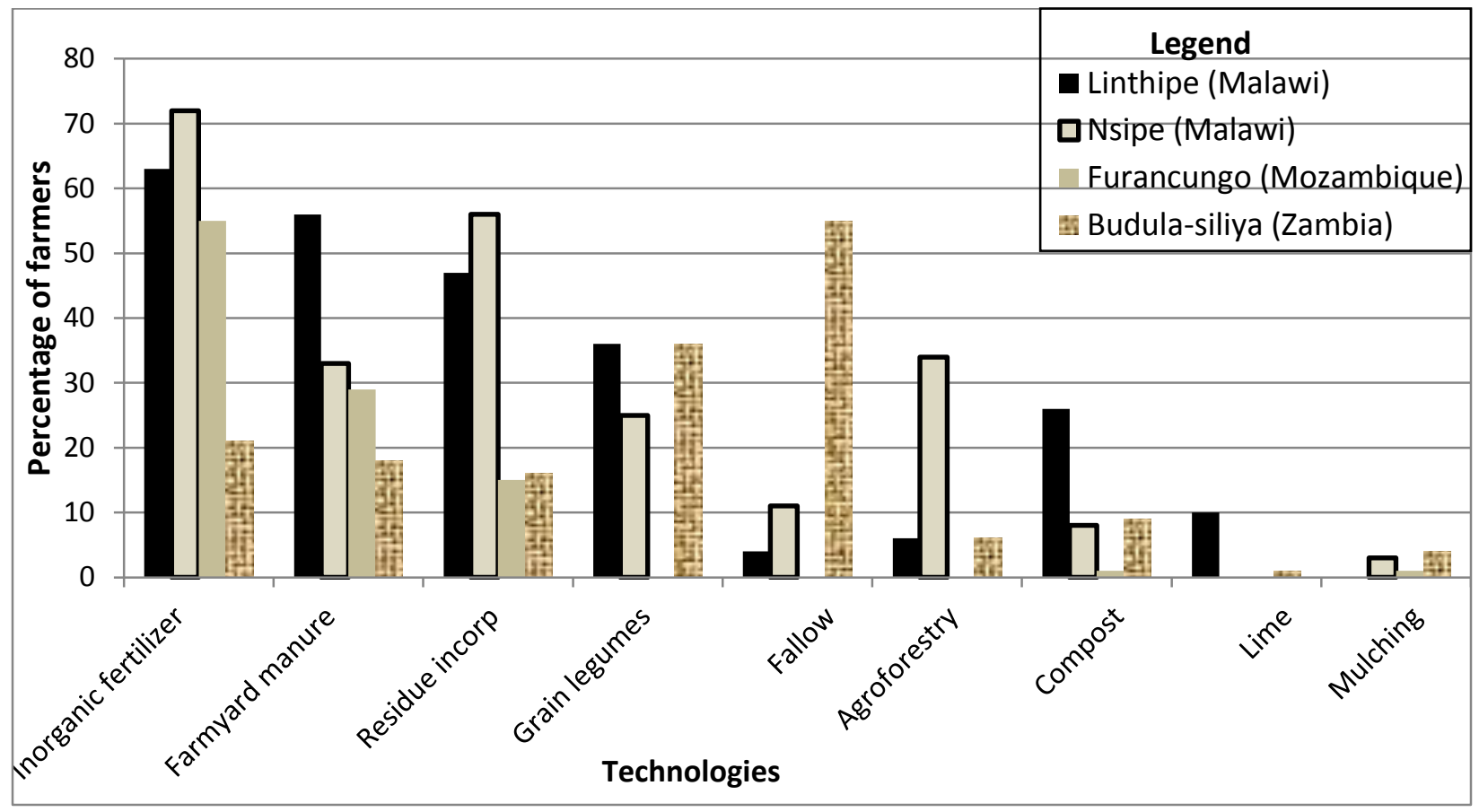

Figure 2. Proportion of farmers using ISFM technologies in the four sites of the Chinyanja triangle

Apart from the traditionally rooted system of rotating crops of different nutrient requirements and pest and disease, incorporation of organic sources is still at lower levels (Figure 2). Slightly above $10 \%$ of the farmers use compost manure or agroforestry. Nutrient analysis of compost manure produced by smallholder farmers in Malawi showed that it contains considerable amounts of nutrients that would boost production (Chilimba et al. 2005). A larger proportion of farmers especially those in the newly opened areas in Budula-siliya put their land to natural fallow. Incorporation of animal waste and crop residues is done by $40 \%$ of farming households. 
Farmers in Linthipe and Nsipe incorporate crop residues immediately after harvest by early ploughing under. Despite the wide cropping of grain legumes as a source of proteins and income, only $30 \%$ of the farmers recognise and use them for soil fertility amelioration. Lime and mulching are the least used in the four sites.

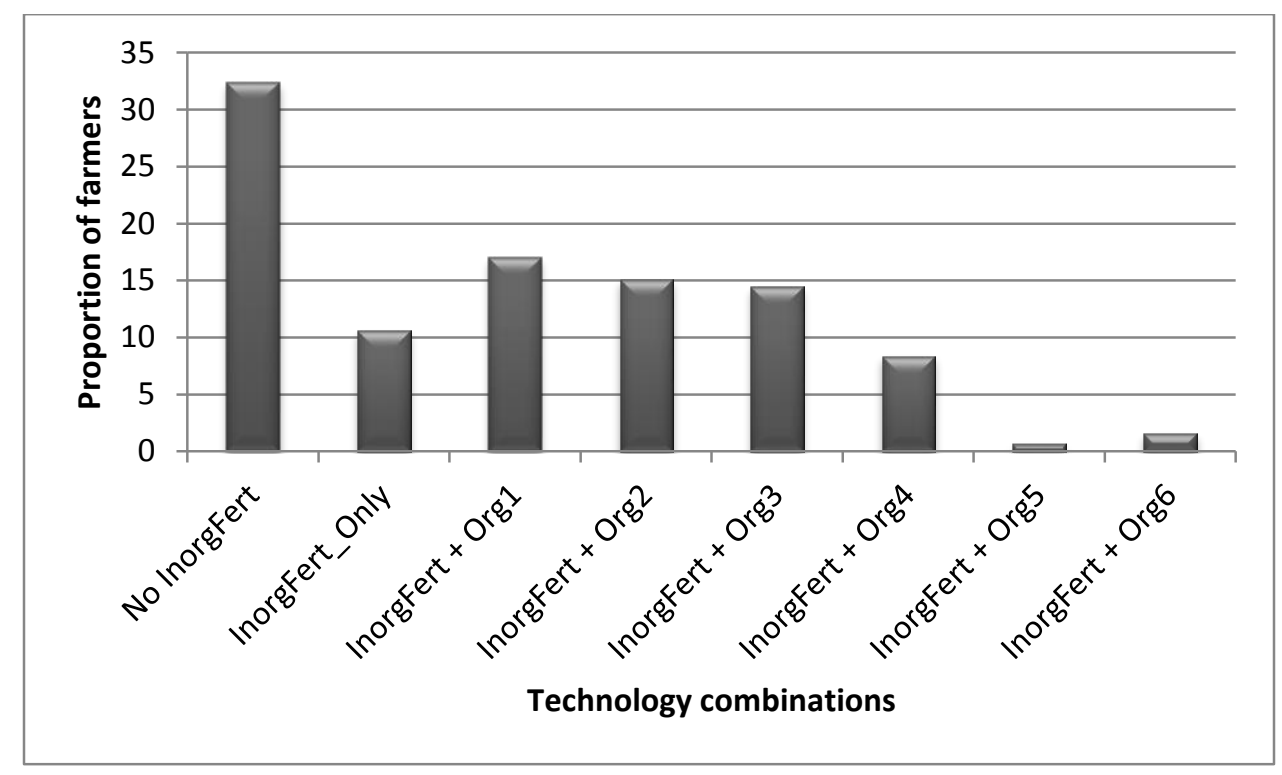

Figure 3. Proportion of households using a number of organic source ISFM technologies used in combination with inorganic fertiliser

There are several possible combinations of the 10 technologies in Figure 2 but the study found that some farmers adopted up to 7 technologies (InorgFert+Org6) (Figure 3). The use of improved germplasm is associated with usage of fertilisers. The choice set is therefore made up of $10 ! / 2 ! 8 !=45$ possible combinations of ISFM technologies considered in this study. Slightly above $34 \%$ of the farmers do not use inorganic fertilizers but are using some of the organic technologies. Moving on to the second ISFM adoption stage, the study reveals that $10 \%$ of the farmers that use fertiliser do not make use of other technologies (InorgFert only). Most farmers use fertilizer plus up to four organic technologies. Several studies show that farmers apply only a subset of technologies, even though applying the whole package would be more profitable (Lambrecht et al. 2014). There are different reasons that can explain this phenomenon. When 
making agricultural management decisions, farmers are constrained by scarcity of finance, labour, land and respond differently depending on one's ability to overcome risk governed by social or cultural settings (Moser and Barrett 2006). Such constraints for different technologies can interact, leading to a socio-economic rationale for inter-relationships in the application of different technologies that possibly masks the biophysical rationale.

\subsection{Set of technologies used}

Hierarchical clustering (Figure 4) shows that common sets of ISFM technologies are: ISFM set1

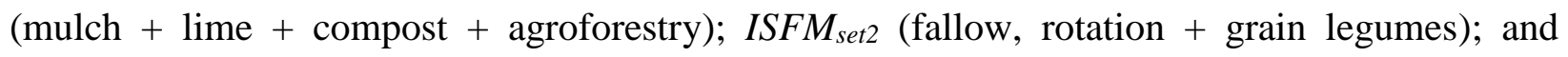
$I S F M_{\text {set } 3}$ (inorganic fertiliser + green manure + farmyard manure). This indicates that in terms of euclidean distance, usage of mulching is dissimilar to Farmyard manure. The three nutrient dense technologies of FYM, green manure and inorganic fertilisers are employed by similar farmers probably due to complementarities among them (Place et al. 2003). Moreover, these technologies yield results in short term since nutrient inputs are readily available and utilised by the crop during the same season. The technological set comprising of fallow, rotation and grain legumes rely on usage of biomass accumulation and nitrogen fixation to rebuild productivity and has complementarity effects as well. In cereal dominated farming system, for decades people have been rotating with short duration improved fallows or leguminous crops to rebuild nitrogen levels (Kwesiga et al. 2005). Benefits from these technologies are realised in the medium to long run by subsequent crops (Muhr et al. 1999). The other four technologies, ISFM setl (mulch, lime, compost and agroforestry) are not very common in the region (Table 1) and hence used by a few individuals to address plot, household specific constraints. Mulching and liming are employed to address challenges of water retention and high acidity, respectively. Use of compost and agroforestry are also observed as viable options for addressing these challenges. With smaller 
node heights (Figure 4), it implies that the cluster (s) formed have smaller dissimilarity between households using the technologies.

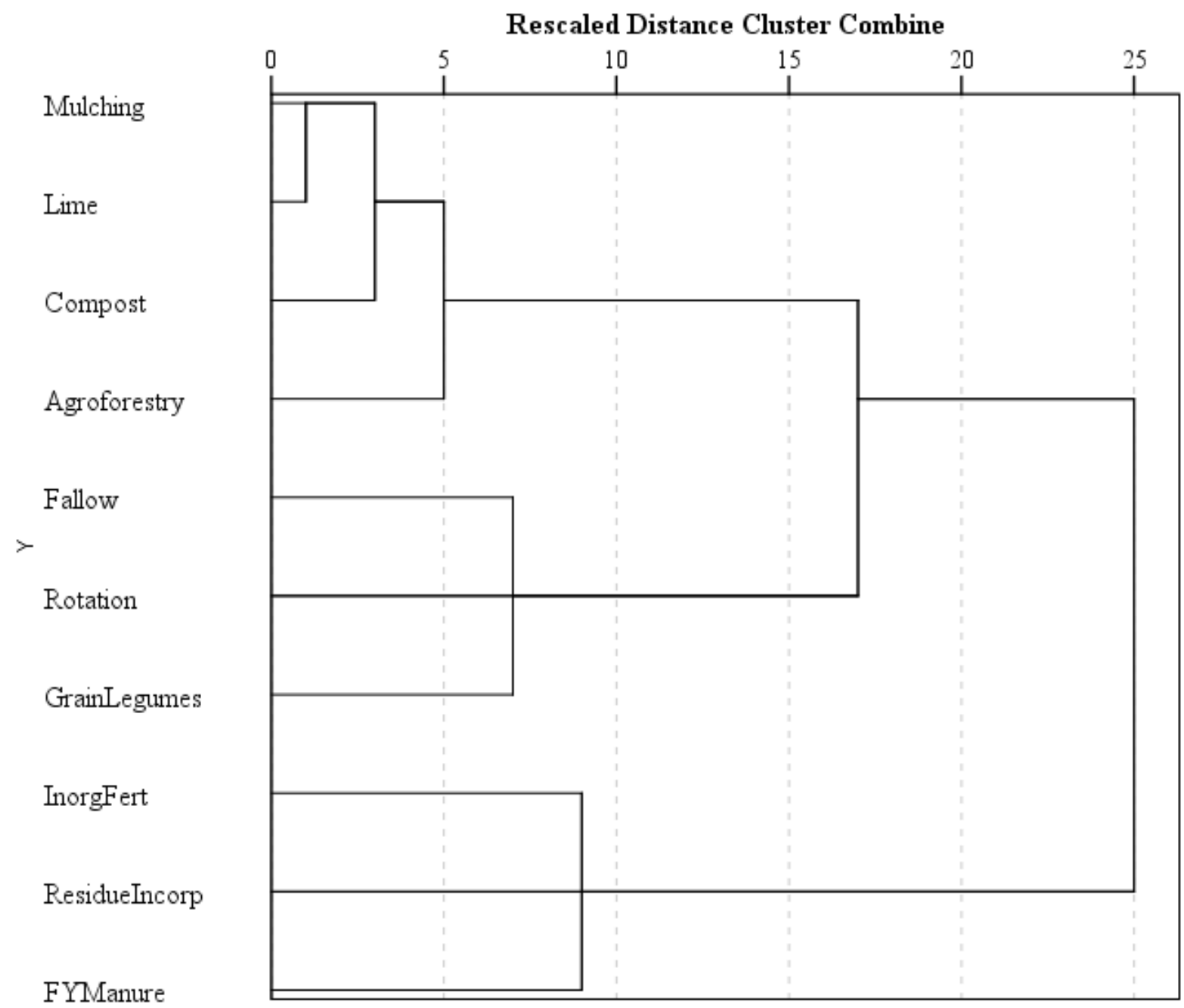

Figure 4. Common combinations of ISFM technologies among sampled households in Chinyanja Triangle.

\subsection{Determinants of ISFM adoption}

Table 1 shows adoption results as modelled by ordered probit function (OPM). Among the various household and farm attributes investigated, some played significant role in technology adoption while some played minimal role. In addition to magnitude, there are also differences in the direction of the effects of the different variables. The results have been presented at two 
levels: combined dataset for all sites for each set of ISFM technologies and at site level for $I S F M_{\text {set3. }}$ The site level model runs for $I S F M_{\text {set } 1}$ and $I S F M_{\text {set } 2}$ could not converge. 
1 Table 1. Determinants of extent of adopting a number of ISFM technologies in Chinyanja Triangle

\begin{tabular}{|c|c|c|c|c|c|c|c|c|c|c|c|c|c|c|}
\hline \multirow[b]{3}{*}{ Variables } & \multirow{2}{*}{\multicolumn{2}{|c|}{$\begin{array}{l}\text { ISFM_set1 } \\
\text { All } 4 \text { sites }\end{array}$}} & \multirow{2}{*}{\multicolumn{2}{|c|}{$\begin{array}{l}\text { ISFM_set2 } \\
\text { All } 4 \text { sites }\end{array}$}} & \multicolumn{10}{|c|}{ ISFM_set3 } \\
\hline & & & & & \multicolumn{2}{|c|}{ All 4 sites } & \multicolumn{2}{|c|}{ Furancungo } & \multicolumn{2}{|c|}{ Budula } & \multicolumn{2}{|c|}{ Nsipe } & \multicolumn{2}{|c|}{ Linthipe } \\
\hline & Coef. & $\mathrm{P}>|\mathrm{z}|$ & Coef. & $P>|z|$ & Coef. & $P>|z|$ & Coef. & $\mathrm{P}>|\mathrm{z}|$ & Coef. & $\mathrm{P}>|\mathrm{z}|$ & Coef. & $\mathrm{P}>|\mathrm{z}|$ & Coef. & $\mathrm{P}>|\mathrm{z}|$ \\
\hline Land size owned +used (acres) & 0.02 & 0.143 & 0.01 & 0.433 & 0.00 & 0.696 & -0.02 & 0.572 & 0.00 & 0.911 & -0.09 & 0.057 & 0.01 & 0.734 \\
\hline Land pieces (number) & 0.01 & 0.894 & -0.10 & 0.100 & 0.10 & 0.100 & 0.24 & 0.165 & -0.19 & 0.192 & -0.19 & 0.337 & 0.52 & 0.003 \\
\hline Soil fertility pe & & & & & & & & & & & & & & \\
\hline ( $2=$ fertile requir & 0.54 & 0.000 & 0.49 & 0.000 & 0.31 & 0.007 & 0.81 & 0.002 & -0.73 & 0.056 & 0.53 & 0.109 & 0.51 & 0.151 \\
\hline ( $3=$ not fertile require more i & 0.09 & 0.564 & 0.26 & 0.044 & 0.17 & 0.151 & -0.13 & 0.668 & -0.23 & 0.547 & 0.26 & 0.449 & 0.19 & 0.555 \\
\hline ( $4=$ infertile does not respond to input) & -0.37 & 0.069 & -0.13 & 0.472 & -0.01 & 0.942 & \multicolumn{2}{|c|}{ (omitted) } & 1.23 & 0.106 & -0.99 & 0.020 & 0.42 & 0.244 \\
\hline Land ownership (1 own; 0 rent/borrow) & -0.10 & 0.661 & 0.05 & 0.803 & 0.07 & 0.732 & 0.93 & 0.554 & 0.58 & 0.174 & 0.80 & 0.284 & -0.23 & 0.557 \\
\hline Gender of $\mathrm{HH}$ head ( $1=$ male; $0=$ female $)$ & 0.20 & 0.450 & 0.11 & 0.611 & 0.25 & 0.200 & 1.00 & 0.062 & 1.05 & 0.120 & -0.10 & 0.854 & -0.45 & 0.415 \\
\hline Age of HH head & -0.01 & 0.362 & -0.01 & 0.366 & 0.00 & 0.613 & -0.04 & 0.093 & 0.00 & 0.941 & -0.03 & 0.275 & 0.00 & 0.956 \\
\hline Farming decision period $\mathrm{H}$ & 0.01 & 0.4 & 0.00 & 0.756 & 0.00 & & 0.04 & 0.051 & -0.01 & 0.749 & 0.03 & & -0.01 & 794 \\
\hline Formal education $\mathrm{HH} \mathrm{l}$ & 0.03 & 0.279 & 0.04 & 0.066 & -0.02 & 0.298 & 0.11 & 0.225 & 0.00 & 0.975 & 0. & 0.0 & -0.02 & 0.699 \\
\hline HH members who read anc & -0.03 & 0.658 & -0.06 & 0.273 & 0.08 & 0.118 & 0.39 & 0.019 & 0.07 & 0.633 & -0.04 & 0.788 & -0.06 & 0.589 \\
\hline Household size & -0.03 & 0.526 & -0.01 & 0.860 & -0.07 & 0.071 & 0.01 & 0.887 & 0.00 & 0.957 & 0.02 & 0.887 & -0.26 & 0.015 \\
\hline Dependency Ratio $(<16+>65) /(17$ to 64$)$ & -0.09 & 0.172 & 0.02 & 0.669 & -0.05 & 0.305 & -0.16 & 0.112 & 0.05 & 0.694 & 0.08 & 0.535 & 0.02 & 0.922 \\
\hline Prod Sell ( $1=$ farm-gate; $0=$ market) & 0.15 & 0.529 & 0.22 & 0.241 & 0.57 & 0.001 & 1.09 & 0.003 & 1.44 & 0.002 & 1.39 & 0.011 & -0.28 & 0.585 \\
\hline Prod Sell (1=individual; $0=$ group) & 0.07 & 0.806 & -0.04 & 0.886 & -0.01 & 0.977 & 0.75 & 0.113 & -1.12 & 0.471 & 1.02 & 0.153 & 0.97 & 0.129 \\
\hline Output market (km) & -0.02 & 0.445 & 0.01 & 0.213 & 0.00 & 0.564 & 0.32 & 0.402 & 0.01 & 0.447 & 0.11 & 0.048 & -0.10 & 0.374 \\
\hline Input market (km) & 0.01 & 0.352 & 0.00 & 0.960 & -0.01 & 0.129 & -0.28 & 0.455 & 0.00 & 0.890 & -0.08 & 0.047 & 0.03 & 0.789 \\
\hline Bicycles owned by HH (n & -0.03 & 0.839 & 0.33 & 0.008 & 0.23 & 0.060 & 0.03 & 0.941 & 0.14 & 0.639 & 0.14 & 0.688 & 0.30 & 0.418 \\
\hline Radios o & 0.20 & 0.193 & -0.06 & 0.627 & 0.03 & 0.785 & -0.19 & 0.488 & 0.38 & 0.248 & 0.26 & 0.533 & -0.10 & 0.786 \\
\hline Cellphones owned by HH (number) & 0.13 & 0.182 & 0.09 & 0.262 & 0.17 & 0.024 & -0.44 & 0.117 & 0.38 & 0.172 & 0.22 & 0.445 & 0.50 & $\mathbf{0 . 0 3 3}$ \\
\hline Tropical livestock units owned by HH & -0.02 & 0.663 & -0.04 & 0.271 & 0.03 & 0.345 & 0.08 & 0.458 & -0.04 & 0.454 & 0.72 & 0.007 & -0.02 & 0.916 \\
\hline & -0 . & & & & & & 61 & 0.000 & 06 & 396 & & 00 & 99 & 0.011 \\
\hline Credit constraint $(2=$ access; $1=$ does not $)$ & -0.01 & 0.977 & 0.48 & 0.004 & 0.07 & 0.672 & -1.07 & 0.086 & 0.82 & $\mathbf{0 . 0 2 3}$ & -1.13 & 0.013 & 0.37 & 0.411 \\
\hline Climate change $(1=$ aware; $0<50 \%)$ & -0.24 & 0.455 & -0.07 & 0.769 & 0.32 & 0.188 & -0.89 & 0.171 & 1.09 & 0.080 & 0.75 & 0.252 & -0.54 & 0.480 \\
\hline Liv & 0. & 0.7 & 0.0 & 0.9 & 0.50 & 0.018 & 0.38 & 0.362 & (om & tted) & 1.57 & 0.042 & 0.89 & 0.118 \\
\hline Crop loss $(1>50 \% ; 0=$ no $)$ & 0.15 & 0.698 & 0.21 & 0.508 & -0.67 & 0.017 & -1.00 & 0.078 & (om & ttea) & -1.10 & 0.174 & -1.08 & 0.059 \\
\hline & -0.36 & & -0.16 & & -0.11 & 0.274 & -0.16 & 0.701 & -0.7 & & -0.0 & 0.789 & 0.65 & 0.101 \\
\hline Contact extension $(1=$ yes; $0=$ no $)$ & 0.19 & 0.345 & -0.13 & 0.459 & 0.10 & 0.505 & -0.20 & 0.588 & -0.03 & 0.965 & -0.80 & 0.065 & 0.94 & 0.025 \\
\hline $\begin{array}{r}\text { Country (1=Malawi) } \\
(2=\text { Mozambique })\end{array}$ & -2.29 & & -1.80 & 0.000 & -1.02 & & & & & & & & & \\
\hline (3=Zambia) & -1.49 & 0.001 & 1.42 & 0.000 & -1.04 & $\mathbf{0 . 0 0 2}$ & & & & & & & & \\
\hline
\end{tabular}




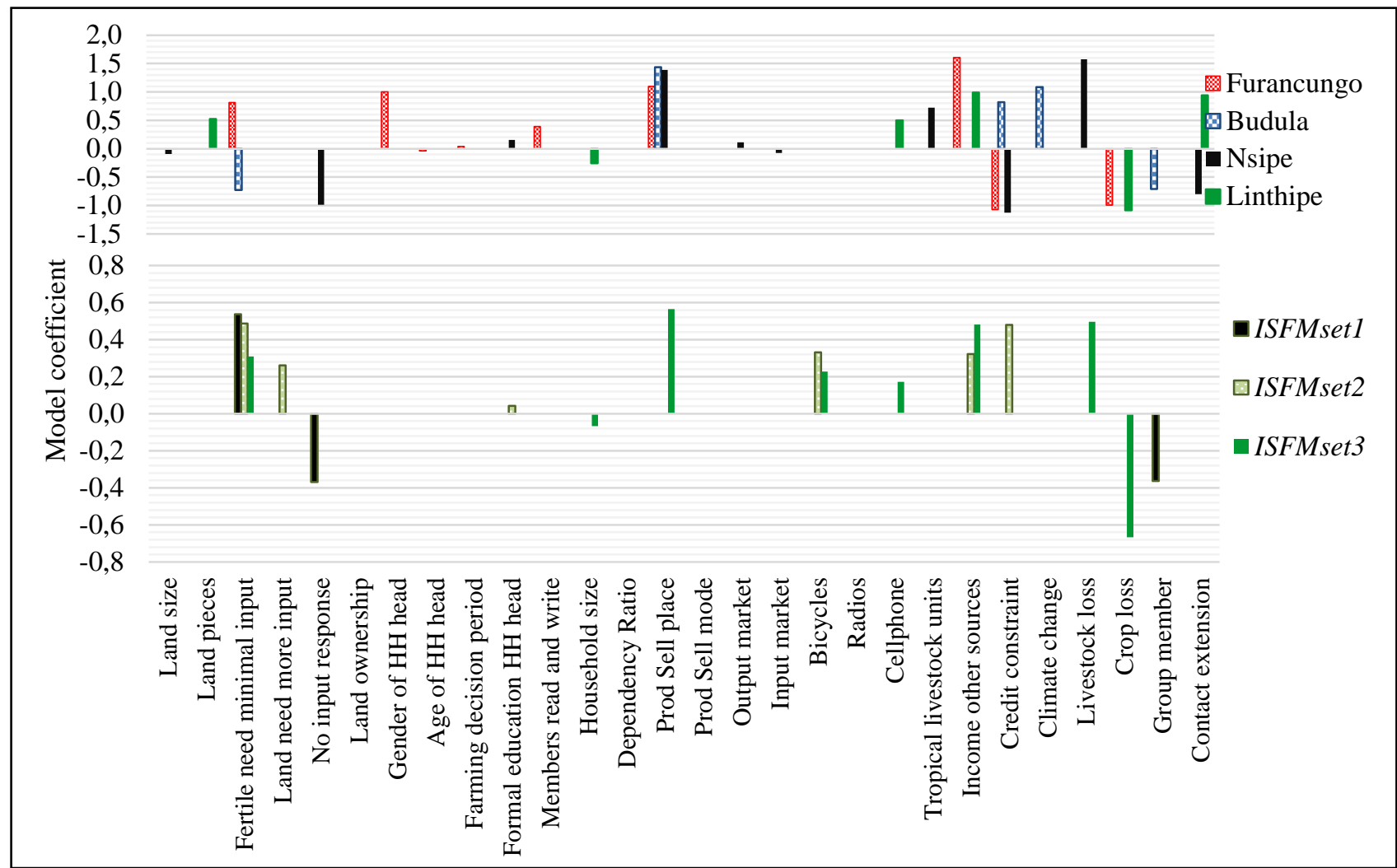

Figure 5: Significant determinants (direction and size of effect) within Chinyanja Triangle for all ISFMsets (lower) and within sites for $I S F M_{\text {set3 }}$ (upper).

The results shows that fertility of land has significant bearing on the farmers' decision to use a number technologies for all $I S F M_{\text {sets. }}$ We see that farmers that perceive their land to require minimal fertility amendments, tend to have higher likelihood of using all ISFM sets. At site level, we also see that perceiving having fertile land that requires minimal inputs increases the likelihood of adopting more technologies of $I S F M_{\text {set } 3}$ in Linthipe in Malawi while the effect is negative in Budula-Siliya in Zambia. Budula is new settlement area whose land could still be fertile, non-responsive (Vanlauwe et al 2011) and single or fewer technologies would be enough to maximise productivity. We see on Figure 2 that usage of IFSM $_{\text {set3 }}$ inorganic fertilizer, farmyard manure and residue incorporation were practiced by fewer $(<20 \%)$ farmers in Budula. 
It is also observed that farmers using more technologies of ISFM $M_{\text {set2 }}$ have land that is perceived to require more inputs. This is the case because the technologies, fallow, rotation and grain legumes are all promoted to address critical soil infertility challenges in farming system and have long term effects capitalising on build-up of organic matter and nitrogen fixation. Therefore, these technologies are used when land is considered to require substantial inputs. Combined use is commonly practiced by rotating cereals with legumes and/or short fallows.

On the other hand, farmers with land that does not respond to inputs have lower

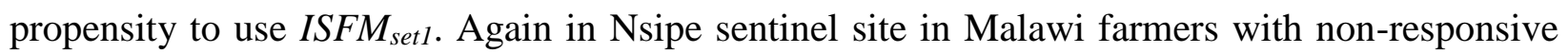
infertile soils are less likely to take more $I S F M_{\text {set } 3}$ technologies. This is the case because nonresponsive soils would require substantial rehabilitation from degradation and investments to achieve this may be too large to be supported by smallholder farm families (Vanlauwe et al. 2011). Framers strive to reclaim degraded land mainly through planting agroforestry trees supported by afforestation programs, though still sporadic (Kamwendo and Sibanda 2015). A community wide sustainable land management program would be required to work out these challenges.

Interesting observation also is that in Nsipe farmers using more $I S F M_{\text {set } 3}$ technologies have less land. This implies that size of land owned by households is one of the most significant physical capital that negatively affect the extent of adoption of ISFM as a package. This finding is not as expected since the general tendency is that large farm sizes are associated with increased availability of financial capital, which can make investment in ISFM more feasible (Akinola and Alene 2010). However, this assertion holds when the dependent variable is amount of land assigned to each technology, a variable used by most studies (Bekele and Drake 2003). Farmers with small land holdings employ a set of best fit technologies in an effort to maintain or 
improve productivity that declines due to continuous cropping. These households need to get the best out of their small plots thus tend to employ more options of improved management. Adoption of more than one ISFM technology by land resource constrained farmers could also be an indication of complementary effects that these technologies share in addressing soil infertility and improving productivity of small-scale farms.

In this study it has been found that most farmers with fragmented plots in Linthipe employ a higher number of $I S F M_{\text {set3 }}$ technologies. Usually farmers employ a small set of best bet technologies on one farm and with fragmentation, the number used by household could be higher. The different fields could be at different topographic sequence requiring different approaches to curtail micro-scale drivers. Having fragmented pieces therefore increases probability of employing more technologies. Studies have shown that land fragmentation has two opposing outputs. On one end, small parcels tend to be more productive than large parcels, because of higher applications of inputs indicating a positive impact of land fragmentation on farmers' income (Niroula and Thapa, 2007). On the other hand, fragmentation compromises the extent to which each of the technologies is used. As noted by Hagazi (2015), land fragmentation is among the root causes of land degradation. When aggregating farms and benefit from economies of scale, recovering the cost of the inputs produced on small fragmented farms has been found to have a negative impact on production efficiency, thereby constraining agricultural development (Niroula and Thapa, 2007).

Among variables for human capital, formal education of household head has positive effect on usage of $I S F M_{\text {set } 2}$ considering the four sampled sites. We also see that at site level, households with heads that attained higher levels of education tend to use more $I S F M_{\text {set3 }}$ in Nsipe. Households with older farmers, more members who can read and write as well as more 
years in farming are more likely to adopt $I S F M_{\text {set3 }}$ technologies in Furancungo in Mozambique. ISFM is considered a knowledge-intensive option which affects its adoption rate necessitating the need for awareness creation and adequate training (Marenya and Barrett 2007, Ngwandu et al. 2014). Most benefits of ISFM technologies are accrued in long term hence requiring a visionary perspective. The extension promotional messages are simplified for farmers with ability to read and write to be able to capture technical information (Oladele et al. 2009). This is based on the premise that technology adoption does not only depend on formal education attained by household members, while for the generally illiterate agrarian community literacy levels in terms of one's ability to read and write is also important (Hojo 2004). More likely, households with longer farming experience have selected from series of technology tests combinations that provides best returns whilst new farmers tend to be risk averse and employ a few options (Grazhdani 2013). With low levels of agricultural extension service (Oladele et al. 2009, Masangano and Mthinda 2012), and particularly in Furancungo Mozambique farmers' own accumulated knowledge becomes important in engaging in ISFM technology testing and evaluation. It is therefore not surprising that literate and those with long farming experience have adopted several technologies to harness complementary benefits.

Gender has been found to be an important aspect in distinguishing $I S F M_{\text {set3 }}$ usage in Furancungo. There is high likelihood of combining inorganic fertilisers with residue incorporation and/or farm yard manure among male headed than female headed households. The observed variations are a result of differing accessibility of the technology between men and women. Studies have found that land owned and managed by women is often underutilized due to lack of sufficient labor, information, education, and resources (Njuki et al. 2008). In many small-holder farms, land management and commercialisation technologies are mostly at the 
disposal of men despite women contribution of $70 \%$ to agricultural production (Lubwana 1999). This puts women at wait and see laggards position.

Households with more members are not implementing $I S F M_{\text {set } 3}$ when considering the entire triangle. The same trend is observed at site level in Linthipe. A common notion is that larger household sizes are normally associated with a higher labour endowment, which would enable a household to accomplish various agricultural tasks (Deressa et al. 2008). However, a negative influence found in this study shows that households with fewer members are the ones that employ more ISFM technologies. This observation supports contrasting theory that households with large families may be forced to divert part of the labour force to off-farm activities in order to earn income for buffering the consumption pressure imposed by a large family (Deressa et al. 2008). The CT region is characterised by food shortage and recurrent hunger and as a consequence households hire out labour to cover the deficit (Whiteside 1999).

Access to markets is considered important variable for ease of access and profitability. Agricultural produce is bulky and with poor road networks, point of sell has important bearing. The study has found that there is high likelihood for farmers selling at farmgate to use more $I S F M_{\text {set } 3}$ in the region and at site level in Furancungo, Budula and Linthipe. This is the as there are fewer formal markets in the region especially for commercial crops such as tobacco and cotton. For most of the produce, most farmers sell at mobile markets operated by unscrupulous vendors. Selling at farmgate therefore gives farmers an advantage to be in a better negotiation position as well as to defer selling to a later date when prices are favourable. Having a nearby output market, where most farmers would sell at the market, deter farmers from adopting more ISFM set3 $_{3}$ technologies. In constract, nearby markets for inputs (negative slope) provides an enabling environment for farmers to use a combination of Inorganic fartilizer, residue 
incorporation and/or farm yard manure. Mobility in terms of owning bicycles, the most common mode of transport, increases propensity of using more $I S F M_{\text {set2 }}$ and $I S F M_{\text {set3 }}$ but has no effect at site level.

Bicycle is the second most important mode of transport for rural communities (Starkey et al. 2002) used by $35 \%$ after using heads $53 \%$ in Chinyanja Triangle and varies across countries with Malawi having more and Mozambique being the least (Amede et al. 2014). The results reflects that and shows that bicycle are important in differentiating farmers' usage of $I S F M_{\text {set2 }}$ and $I S F M_{\text {set3 } 3}$ within the region but without significant differences within sites. The technologies of grain legumes used in rotation, inorganic fertilizer, and farm yard manure are labour and cash intensive, thus a better return on investment spur on the farmers. Farmers with bicycles are able to take their produce to distant markets (positive slope) and fetch good prices, thereby having an incentive to invest in more ISFM technologies. Other studies found positive effects of bicycles on agricultural productivity (Kassali et al. 2012)

Telecommunication is becoming an important mode of agricultural service delivery and information sharing among smallholder farmers (Mittal and Tripathi 2009; Baumuller, 2012). We see that owning a mobile phone significantly influences households' usage of $I S F M_{\text {set } 3}$ in region and particularly, influenced adoption in Linthipe. This implies that it is more likely that farmers without cellphones could be incentivised to adopt ISFM if they can access cellphones. Belonging to groups, is also expected to positively influence adoption of ISFM. This is so because, in small holder farming systems, most farmers are pro-poor and groups are the social capital (Njuki et al. 2008). In this study, however, we have found a negative influence on adoption of $I S F M_{\text {setl }}$. The negative correlation is supported by the work of ... who found that farmers mostly join non-farming groups and those that join farming are mostly for marketing. In 
the earlier observation, we saw above that farmers who sell in groups have lower likelihood to use ISFM technologies. It could also be that farmers using $I S F M_{\text {set } 1}$ such as liming and mulching deal with specific constraint that would not depend on social networks. Moreover, groups being a bonding social capital significant at promoting diversified adoption and use of improved innovations (Njuki et al. 2008). They are instead essential in influencing the adoption of one type of improved technology (Winters et al. 2006).

Farming in the region though dominated by crops, some farmers practice integrated croplivestock systems. Livestock contributes to ISFM within cropping system in various ways but directly through dung used as farm yard manure. The results from this study shows that livestock ownership contributes significantly to households using more $I S F M_{\text {set3 }}$ technologies in Nsipe. Farmers with livestock thus are apply in combination, farm yard manure with inorganic fertilizer and/r residue incorporation. In rural communities, despite farming being the main livelihood source, most people engage in off-farm activities to supplement either food or cash income needs. In most instances, farmers have several livelihood portfolios and tend to transfer revenues from one into another, creating interrelationships between activities during different times of the year. Being a complementary activity, we see in this study that households with off-farm activities have high propensity to use more technologies of $I S F M_{s e t 2}$ and $I S F M_{\text {set } 3}$ in the region. Off farm income is principally important in Furancungo and Linthipe, where in both sites farmers without off-farm income sources tend to use fewer of $I S F M_{\text {set3 }}$ technologies.

Credit constrained, defined in this paper as those farmers who need credit but do not have access or applied but were not given, assumed to deter number of ISFM used. Apparently, the analysis using the four sites shows that households using $I S F M_{\text {set2 }}$ are not credit constrained i.e. either they have access to credit or they do not need it. Except for grain legumes, the two other 
technologies: rotation and fallow do not require capital investment hence it is more likely that the practicing these is not associated with credit. At site level, for $I S F M_{\text {set3 }}$, resource rich farmers with access plus those that do not need credit use more $I S F M_{\text {set } 3}$ in Bundula but opposite effect is observed in Furancungo and Nsipe. Budula is a newly opened area with relatively fertile soils, which do not require large inputs to require a credit. On the other hand, farmers in Furancungo and Nsipe with soils that require more inputs would need more financial resources but credit sources are limited.

We see that farmers that are aware of climate change tend to implement more ISFM $_{\text {set3 }}$ in Budula_Siliya in Zambia. IFM is being promoted as one avenue to cushion against shocks in the farming system. However, the level of risk that farmers can bear sometimes exceed the threshold. We see in this study that farmers can manage to invest in $I S F M_{\text {set } 3}$ after a major loss of livestock species. However, farmers that lost a greater share of crops seem not to undertake

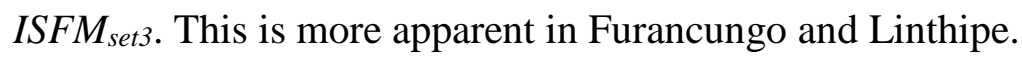

The extension service is used to deliver best practices to farmers and those in contact are expected to be better able to implement ISFM technologies. We have lessons from two Malawian sites where we see contrasting effects. In Linthipe, there are several projects that implements ISFM technologies and it happens to have positive influence. On the other hand, in Nsipe, there are fewer organisations and farmers that rely on extension officers for advice tend to have fewer options for $I S F M_{\text {set3 } 3}$ to use. It can be asserted that fewer number of extension officers, there is high likelihood that farmers get advice on a few topics. 


\subsection{Conclusion}

The study explored socioeconomic attributes and biophysical factors determining farmers' choice of a set of ISFM technologies used. It has been shown that farmers' adoption of more than one technology is positively influenced by land fragmentation, literacy and experience with farming, gender of household head and wealth index. Factors exerting negative influence include size of the household and land used/owned. This shows that resource endowments lowers farmers propensity to adopt multiple ISFM technologies. Farmers with resources chose from a wide range of ISFM options, a few best bets with complementarities that enhance productivity. On the other hand those with small land holdings tend to adopt more ISFM technologies.

The positive influence observed among farmers with higher literacy indicates that they are the ones that test/practice several technologies to harness full benefits of IFSM. These farmers are better able to bear risk. However, with the lower education levels of adult household heads that make most of the decisions, there is need for adult literacy learning through demonstrations and farmer schools to ensure that they are able to process information and make informed decisions regarding improvement of farmland productivity.

The results have several implications for programs that scale-out ISFM technologies in the resource constrained farming households of Chinyanja Triangle. It is important to take into account complementarities among the technologies so as to hasten uptake by farmers at different socio-ecological levels. The farming systems dominated by small to medium scale farmers provide a platform for development of technologies that utilise local resources. However it is also important to consider heterogeneity in farmers and their farms. 


\section{Acknowledgement}

This work was undertaken as part of, and funded by, the CGIAR Research Program on Dryland Systems implemented by the International Center for Tropical Agriculture (CIAT). The opinions expressed here belong to the authors, and do not necessarily reflect those of Dryland Systems,

CIAT, or CGIAR. Additional data collection was supported by Africa RISING project USAID funded

\section{References}

Ajayi, O.C. et al. (2008). Adoption, Profitability, Impacts and Scaling-Up of Agroforestry Technologies in southern African countries. ICRAF, Lilongwe.

Ajayi, O.C., et al. (2007). Adoption of renewable soil fertility replenishment technologies in the southern African region: Lessons learnt and the way forward. Natural Resources Forum, 31, 306-317.

Akinola, A.A. and Alene, A.D. (2010). Determinants of adoption and intensity of use of balance nutrient management systems technologies in the northern Guinea savannah of Nigeria. Quarterly Journal of International Agriculture, 49 (1), 25-45

Amede T., et al. (2014). The Chinyanja Triangle in the Zambezi River Basin, southern Africa: status of, and prospects for, agriculture, natural resources management and rural development. WLE Research for Development (R4D) Learning Series 1 [online]. Available from:

http://www.iwmi.cgiar.org/Publications/wle/r4d/wle_research_for_developmentlearning_series-1.pdf [Accessed 20 September 2014].

Asfaw, S., et al. (2011). Agricultural technology adoption, seed access constraints and commercialization in Ethiopia. Journal of Development and Agricultural Economics, 3 (9), 436-447

Baumuller, H. (2012). Facilitating agricultural technology adoption among the poor: The role of service delivery through mobile phones. Working Paper Series 93, Center for Development Research, University of Bonn: Bonn. 
Bekele, W. and Drake, L. (2003). Soil and water conservation decision behavior of subsistence farmers in the Eastern Highlands of Ethiopia: a case study of the Hunde-Lafto area. Ecological Economics, 46, 437-451.

Benson, T. (1999). Area specific fertiliser recommendations for hybrid maize grown by Malawi smallholder. Lilongwe: Chitedze Agricultural Research Station.

CGIAR (2014). Chiefs in Chinyanja Triangle [online]. Available from: www.youtube.com/watch?v=TX1b1a_64dM [Accessed 24 November 2014].

Chilimba, A.D.C., et al. (2005). Quality assessment of compost manure produced by smallholder farmers in Malawi [online]. Available from: http://www.ndr.mw:8080/xmlui/handle/123456789/350 [Accessed 02 February 2013].

Chinangwa, L.L.R. (2006). Adoption of soil improvement technologies among smallholder farmers in southern Malawi [online]. Available from: http://www.umb.no/statisk/noragric/publications/master/2006_linda_chinangwa.pdf [Accessed 27 July 2014].

Chilonda, P. and Otte, J. (2006). Indicators to monitor trends in livestock production at national, regional and international levels. Livestock Research for Rural Development, 18 (6).

Cornish, R. (2007). Cluster analysis [online]. Available from: http://www.statstutor.ac.uk/resources/uploaded/clusteranalysis.pdf [Accessed 12 February 2013].

Denning, D., et al. (2009). Input Subsidies to Improve Smallholder Maize Productivity in Malawi: Toward an African Green Revolution. PLoS Biology, 7 (1).

Deressa, T., et al. (2008). Analyzing the determinants of farmers' choice of adaptation methods and perceptions of climate change in the Nile basin of Ethiopia [online]. Available from: http://www.ifpri.org/sites/default/files/publications/ifpridp00798.pdf [Accessed 05 January 2014].

Dorfman, J.H. (1996). Modelling multiple adoption decisions in a joint framework. American Journal of Agricultural Economics, 78, 547-557.

FAO (2014). FAOSTAT [online]. Available from: ftp://extftp.fao.org/ES/Reserved/essb/ess/ftp_essb/FAOSTAT/BulkDownloads/FAOSTAT.zip [Accessed 25 June 2014]. 
Filmer, D. and Pritchett, L.H. (2001). Estimating wealth effects without expenditure data - or tears: an application to educational enrolments in states of India. Demography, 38, 115132.

Fisher, M. and Mazunda, J. (2011). Could low adoption of modern maize varieties in Malawi be explained by farmers' interest in diverse seed characteristics? IFPRI: Malawi Strategy Support Program (MaSSP) Policy note 7.

Foltz, J.D. (2003). The economics of water-conserving technology adoption in Tunisia: an empirical estimation of farmer technology choice. University of Chicago: EDCC v51n2 510205.

Freese, J. and Long, J. S. (2000). sg155: Tests for the multinomial logit model. Stata Technical Bulletin, 58, 19-25

Golob, T.F. and Regan, A.C. (2002). Trucking industry adoption of information technology: a structural multivariate discreet choice model. University of California: Working Paper UCI-ITS-WP-98-10.

Grazhdani, D. (2013). An analysis of factors affecting the adoption of resource conserving agricultural technologies in Al-Prespa Park. Natura Montenegrina, Podgorica, 12 (2), 431-443.

Guastella, G., et al. (2013). Investment behaviour of EU arable crop farms in selected EU countries and the impact of policy reforms. Brussels, Centre for European Policy Studies (CEPS): Factor Markets Working Paper No. 42/May 2013.

Hojo, M. (2004). Measuring Education Levels of Farmers: Evidence from Innovation Adoption in Bangladesh. Osaka School of International Public Policy: Discussion Paper 04-06.

Holden, S. and Mangisoni, J. (2013). Input subsidies and improved maize varieties in Malawi: what can we learn from the impacts in a draught year? Norwegian University of Life Sciences: Centre for Land Tenure Studies Working Paper 07/13.

IBM (2012). Hierarchical cluster analysis measures for binary data. New York: IBM SPSS Statistics for Windows, Version 21.0.

Kamwendo, C. and Sibanda, H. (2015). Building Community Resilience with SLM : A Case for Malawi. Journal of Environment and Earth Science, 5 (7), 11-15. 
Kassali, R. F. (2012). Effect of rural transportation system on agricultural productivity in Oyo State, Nigeria. Journal of Agriculture and Rural Development in the Tropics and Subtropics, 113 (1), 13-19.

Kassie, M., et al. (2015). Understanding the adoption of a portfolio of sustainable intensification practices in eastern and southern Africa. Land Use Policy, 42, 400-441.

Kwesiga, F., et al. (2005). Improved fallows in Eastern Zambia: History, farmer practice and impacts. Lusaka: Paper presented at the IFPRI workshop on Success in African Agriculture, held from 10-11 June 2002.

Lambin, E.F. and Geist, H.J., eds. (2008). Land-Use and Land-Cover Change: Local Processes and Global Impacts. New York: Springer Science \& Business Media.

Lambrecht, I., Vanlauwe, B. and Maertens, M. (2014). Integrated soil fertility management: From concept to practice in eastern DR Congo. University of Leuven: Bio economics Working Paper Series, WP 2014/5.

Le Q.B., Seidl R. and Scholz R.W. (2012). Feedback loops and types of adaptation in the modelling of land-use decisions in an agent-based simulation. Environmental Modelling and Software, 27 (28), 83-96.

Lubwana, F.B. (1999). Socio-economic and gender issues affecting the adoption of conservation tillage practices. In: Kaumbutho P.G. and Simalenga T.E., eds. Conservation tillage with animal traction. Harare: A resource book of the Animal Traction Network for Eastern and Southern Africa (ATNESA), 173p.

Marenya, P.P. and Barrett, C.B. (2007). Household-level determinants of adoption of improved natural resources management practices among smallholder farmers in western Kenya. Food Policy, 32 (4), 515-536.

Masangano C. and Mthinda C. (2012). Pluralistic extension system in Malawi. IFPRI: Discussion Paper 01171.

McKelvey, R. and Zavoina, W. (1975). A Statistical Model for the Analysis of Ordinal Level Variables. Journal of Mathematical Sociology, 4, 103-20.

Mittal S and Tripathi G. (2009). Role of Mobile Phone Technology in Improving Small Farm Productivity. Agricultural Economics Research Review, 22, 451-459.

Morris, M., et al. (2007). Fertilizer use in African agriculture lessons learned and good practice guidelines. World bank: Agriculture and Rural development 39037. 
Moser, C., Barrett, C.B. (2006). The complex dynamics of smallholder technology adoption: the case of SRI in Madagascar. Agricultural Economics, 35, 373-388.

Muhr, L., et al. (1999). Forage legumes for improved fallows in agro-pastoral systems of sub humid West Africa: III. Nutrient import and export by forage legumes and their rotational effects on subsequent maize. Tropical grasslands, 33, 245-256.

Mugwe, J., et al. (2009). Determinants of the decision to adopt integrated soil fertility management practices by smallholder farmers in the central highlands of Kenya. Experimental Agriculture, 45 (01), 61-75.

Mueller, N.D., et al. (2012). Closing yield gaps through nutrient and water management. Nature, Vol 000 .

Murtagh, F., Legendre, P. (2014). Ward's Hierarchical Agglomerative Clustering Method: Which Algorithms Implement Ward's Criterion? Journal of Classification, 31, 274-295

Myburgh, M. and Brown, J. (2006). The potential of information and communication technology as an enabler for agricultural and community development in the Chinyanja Triangle. Dennesig, South Africa: Agribusiness in Sustainable Natural African Plant Products (ASNAPP).

Ngwandu, T., et al. (2014). Factors influencing access to integrated soil fertility management information and knowledge and its uptake among smallholder farmers in Zimbabwe. Journal of Agricultural Education and Extension, 20 (1), 79-93.

Niroula, G.S. and Thapa, G.B. (2007). Impacts and causes of land fragmentation, and lessons learned from land consolidation in South Asia. Land Use Policy, 22, 358-372.

Niroula, G.S. and Thapa, G.B. (2007). Impacts of land fragmentation on input use, crop yield and production efficiency in the mountains of Nepal. Land degradation \& development, 18 (3), 237-248.

Njuki, J.M., Mapila, M.T., Zingore, S. and Delve, R. (2008). The dynamics of social capital in influencing use of soil management options in the Chinyanja Triangle of southern Africa. Ecology and Society, 13 (2), 9.

Odendo, M., Obare, G. and Salasya, B. (2010). Determinants of the speed of adoption of soil fertility enhancing Technologies in western Kenya. Cape Town, South Africa: Paper presented at the Joint 3rd African Association of Agricultural Economists (AAAE) and 
48th Agricultural Economists Association of South Africa (AEASA) Conference, September 19-23, 2010.

Oladele, O.I., Lepetu, J. and Subair, S.K. (2009). SWOT Analysis of extension systems in southern African countries. Journal of Agriculture and Environment for International Development, 103 (4), 309-320.

Pattanayak, S.K., et al. (2003). Taking stock of agroforestry adoption studies. Agroforestry Systems, 57, 173-186.

Place, F., et al. (2003). Prospects for integrated soil fertility management using organic and inorganic inputs: evidence from smallholder African agricultural systems. Food Policy, 28, 365-378.

Ray P. (1973). Independence of irrelevant alternatives. Econometrica, 41 (5), 987-991.

Republic of Malawi (2008). 2008 population and housing census: preliminary report. Zomba: National Statistical Office.

Republica de Mocambique (2005). Perfil do Distrito de Macanga, Provincia de Tete. Maputo: Ministrerio da Administracao Estatal.

Republic of Zambia (2012). 2010 census of population and housing. Volume 11: National descriptive tables. Lusaka: Central Statistical Office.

Sekeris, P. (2010). Land Inequality and Conflict in Sub-Saharan Africa. Peace Economics, Peace Science and Public Policy, 16 (2), 10.

Starkey, P. et al. (2002). Improving Rural Mobility: Options for Developing Motorized and Nonmotorized Transport in Rural Areas. World Bank Technical Paper No. 525, Washington, DC: World Bank.

The Montpellier Panel (2013). Sustainable Intensification: A new Paradigm for African Agriculture. London.

UNICEF (2013). Improving child nutrition: The achievable imperative for global progress. New York: United Nations Children's Fund.

Vanlauwe, B., et al. (2011). Integrated soil fertility management: operational definition and consequences for implementation and dissemination. Outlook on Agriculture, 39, 17-24.

Vagen, T., et al. (2013). The Land Degradation Surveillance Framework: Field Guide. Nairobi: CIAT/ICRAF. 
Vyas, S. and Kumaranayake, L. (2006). Constructing socio-economic status indices: how to use principal components analysis. Health Policy Plan, 21(6), 459-468.

Whiteside, M. (1999). Ganyu labour in Malawi and its implications for livelihood security interventions: An analysis of recent literature and implications for poverty alleviation. ODI/AgREN, Netwrok paper no. 99.

Winters, P., Cavatassi, R. and Lipper, L. (2007). Sowing the seeds of social relations. The role of social capital in crop diversity. Department of Economics, American University, Washington D.C.

Wiredu, A.N., Martey, E. and Fosu, M. (2014). Describing Adoption of Integrated Soil Fertility Management Practices in Northern Ghana. Prague, Czech Republic: Paper presented at the Conference on International Research on Food Security, Natural Resource Management and Rural Development.

Yengoh, G.T. (2012). Determinants of yield differences in small-scale food crop farming systems in Cameroon. Agriculture and Food Security, 1:19. 